\title{
Equilibrium and Kinetics Study of Adsorption of Crystal Violet onto the Peel of Cucumis sativa Fruit from Aqueous Solution
}

\author{
T. SMITHA ${ }^{\mathrm{A}}$, S. THIRUMALISAMY ${ }^{\mathrm{A}^{*}}$, and S. MANONMANI ${ }^{\mathrm{B}}$ \\ ${ }^{a}$ Department of Chemistry, Karpagam University, \\ Coimbatore-641021, India. \\ ${ }^{\mathrm{b}}$ Department of Chemistry, PSG College of Arts and Science, \\ Coimbatore-641014, India
}

Received 23 January 2011; Accepted 18 March 2011

\begin{abstract}
The use of low-cost, locally available, high efficiency and ecofriendly adsorbents has been investigated as an ideal alternative to the current expensive methods of removing dyes from wastewater. This study investigates the potential use of the peel of Cucumis sativa fruit for the removal of crystal violet $(\mathrm{CV})$ dye from simulated wastewater. The effects of different system variables, adsorbent dosage, initial dye concentration, $\mathrm{pH}$ and contact time were investigated and optimal experimental conditions were ascertained. The results showed that as the amount of the adsorbent increased, the percentage of dye removal increased accordingly. Optimum $\mathrm{pH}$ value for dye adsorption was determined as 7.0. The adsorption of crystal violet followed pseudosecond -order rate equation and fit well Langmuir and Freundlich equations. The maximum removal of $\mathrm{CV}$ was obtained at $\mathrm{pH} 7$ as $92.15 \%$ for adsorbent dose of $0.2 \mathrm{~g} / 50 \mathrm{~mL}$ and $25 \mathrm{mg} \mathrm{L}^{-1}$ initial dye concentration at room temperature. The maximum adsorption capacity obtained from Langmuir equation was $34.24 \mathrm{mg} \mathrm{g}^{-1}$. Furthermore, adsorption kinetics of (CV) was studied and the rate of adsorption was found to conform to pseudo-second order kinetics with a good correlation $\left(\mathrm{R}^{2}>0.9739\right)$. The peel of Cucumis sativa fruit can be attractive options for dye removal from diluted industrial effluents since test reaction made on simulated dyeing wastewater show better removal percentage of $(\mathrm{CV})$.
\end{abstract}

Keywords: Cucumis sativa; Adsorption; Wastewater; Crystal Violet; Kinetics; Activated carbon.

\section{Introduction}

Industrial effluents are one of the major causes of environmental pollution because effluents discharged from dyeing industries are highly colored with a large amount of suspended organic solid ${ }^{1 .}$ Untreated disposal of this colored water into the receiving water body either causes damage to aquatic life or to human beings by mutagenic and carcinogenic effect. As a matter of fact, the discharge of such effluents is worrying for both toxicological and environmental reasons ${ }^{2,3}$. 
Conventional wastewater treatment methods for removing dyes include physicochemical, chemical and biological methods, such as coagulation and flocculation ${ }^{4}$, adsorption $^{5}$, ozonation ${ }^{6}$, electrochemical techniques ${ }^{7}$, and fungal decolonization ${ }^{8}$. Among these methods adsorption has gained favour in recent years due to proven efficiency in the removal of pollutants from effluents to stable forms for the above treatment methods ${ }^{1}$. Activated carbon, as an adsorbent has been widely investigated for the adsorption of dyes ${ }^{9}$, but its high cost limits its commercial application. In recent years, there has been growing interest in finding inexpensive and effective alternatives to carbon, such as clay minerals ${ }^{10}$, fly ash ${ }^{11}$, peat ${ }^{12}$, wood powder ${ }^{13}$, coir pith ${ }^{14,15}$ and lignin ${ }^{16}$.

Cucumis sativa is a local fruit available in abundance throughout the year. The peel of Cucumis sativa fruit, which is removed before consumption is a waste product which is usually discarded. Local vendors at a railway level cross (Near Eachnari, Coimbatore, Tamil $\mathrm{Nadu}$ ) sell about 600 to $700 \mathrm{~kg}$ of the fruit everyday, at this one locale, about $3 \%$ of this accounts as waste. Since the peel of Cucumis sativa fruit is available free of cost, Therefore the main objective of this study was to evaluate the possibility of using dried peel of Cucumis sativa to remove crystal violet from simulated wastewater. Peel of Cucumis sativa fruit was previously investigated to adsorb cationic dyes ${ }^{17}$. Systematic evaluation of the parameters involved, such as $\mathrm{pH}$, adsorbent dose, adsorbent particle size, initial dye concentration and time.

\section{Experimental}

Preparation of the peel of Cucumis sativa fruit (CCS)

The peel of Cucumis sativa fruit was obtained from local vendors, Eachnari railway Gate, Coimbatore District (Tamil Nadu). Then the material was washed with distilled water and dried at $110 \pm 2^{\circ} \mathrm{C}$ It was air- dried and powdered in a grinder. The dry biomass was crushed into granules, sieved to different particle sizes, and then preserved in desiccators for use.

\section{Preparation of synthetic solutions}

A stock solution of $500 \mathrm{mg} \mathrm{L}-1$ was prepared by dissolving the appropriate amount of CV (obtained from s.d.Fine Chemicals, Mumbai, India) in $100 \mathrm{~mL}$ and completed to $1000 \mathrm{~mL}$ with distilled water. Different concentrations ranged between 25 and $200 \mathrm{mg} \mathrm{L} \mathrm{-1} \mathrm{of} \mathrm{(CV)}$ were prepared from the stock solution. All the chemicals used throughout this study were of analytical-grade reagents. Double-distilled water was used for preparing all of the solutions and reagents. The initial $\mathrm{pH}$ is adjusted with $0.1 \mathrm{M} \mathrm{HCl}$ or $0.1 \mathrm{M} \mathrm{NaOH}$. All the adsorption experiments were carried out at room temperature $(27 \pm 20 \mathrm{C})$.

\section{Batch adsorption studies}

\section{Effect of pH on $\mathrm{CV}$ adsorption}

The effect of $\mathrm{pH}$ on the equilibrium uptake of dyes was investigated by employing initial concentration of CV $(100 \mathrm{mg} / \mathrm{L})$ and $0.2 \mathrm{~g} / 50 \mathrm{~mL}$ of CS. The initial $\mathrm{pH}$ values were adjusted with $0.1 \mathrm{M} \mathrm{HCl}$ or $\mathrm{NaOH}$ to form a series of $\mathrm{pH}$ from 2 to 10 . The suspensions were shaken at room temperature $(27 \pm 20 \mathrm{C})$ using agitation speed $150 \mathrm{rpm}$ for the minimum contact time required to reach the equilibrium $90 \mathrm{~min}$ and the amount of ( $\mathrm{CV}$ ) adsorbed determined.

\section{Effect ofCCS dose on $\mathrm{CV}$ adsorption}

The effect of adsorbents dose on the equilibrium uptake of CV (100 mg L-1) was investigated with CCS concentrations of $0.2,0.4$ and $0.6 \mathrm{~g} / 50 \mathrm{~mL}$. The experiments were performed by shaking known (CV) concentration with the above different CCS 
concentrations to the equilibrium uptake $90 \mathrm{~min}$ and the amount of (CV) adsorbed determined.

\section{Kinetics studies}

Adsorption studies were conducted in 250-mL shaking flasks at solution $\mathrm{pH}$ 7.0. CCS $(0.2 \mathrm{~g} / 50 \mathrm{~mL})$ was thoroughly mixed individually with $50 \mathrm{~mL}$ of $(\mathrm{CV})$ solution $100 \mathrm{mg} / \mathrm{L}$ and the suspensions were shaken at room temperature. Samples of $1.0 \mathrm{~mL}$ were collected from the duplicate flasks at required time intervals viz.10, 20, 30, 40, 50, 60, 70, 80, and $90 \mathrm{~min}$ and were centrifuged for $5 \mathrm{~min}$. The clear solutions were analyzed for residual (CV) concentration in the solutions.

\section{Adsorption isotherm}

Batch adsorption experiments were carried out in a rotary shaker at $150 \mathrm{rpm}$ using $250 \mathrm{ml}-$ shaking flasks at room temperature for $90 \mathrm{~min}$. The CCS $(0.2 \mathrm{~g})$ was thoroughly mixed with $50 \mathrm{~mL}$ of $(\mathrm{CV})$ solutions. The isotherm studies were performed by varying the initial (CV) concentrations from 25 to $200 \mathrm{mg} / \mathrm{L}$ at $\mathrm{pH} 7.0$, which was adjusted using $0.1 \mathrm{M} \mathrm{HCl}$ or 0.1 $\mathrm{M} \mathrm{NaOH}$ before addition of CCS and maintained throughout the experiment. After shaking the flasks for $90 \mathrm{~min}$, the reaction mixture was analyzed for the residual $(\mathrm{CV})$ concentration.

The concentration of (CV) in solution was measured by using a direct $\mathrm{UV}$-vis spectrophotometric method using Systronic Spectrophotometer-104 at wavelength $480 \mathrm{~nm}$. All the experiments are duplicated and only the mean values are reported. The maximum deviation observed was less than $\pm 4 \%$.

Adsorption of (CV) from simulated wastewater was studied using $0.2 \mathrm{~g} / 50 \mathrm{~mL}$ of CCS and $(\mathrm{CV})$ concentrations $100 \mathrm{mg} / \mathrm{L}$ at initial $\mathrm{pH}$ 7.0. The amount of dye adsorbed at equilibrium onto carbon, qe $(\mathrm{mg} / \mathrm{g})$, was calculated by the following mass balance relationship:

$$
\mathrm{q}_{\mathrm{e}}=\left(\mathrm{C}_{0}-\mathrm{C}_{\mathrm{e}}\right) \mathrm{V} / \mathrm{W}
$$

where $\mathrm{C} 0$ and $\mathrm{Ce}(\mathrm{mg} / \mathrm{L})$ are the initial and equilibrium liquid -phase concentration of (CV), respectively, $\mathrm{V}$ the volume of the solution(L), and $\mathrm{W}$ is the weight of the CCS used(g).

\section{Results and Discussion}

\section{Adsorbent characterization}

Characteristics of activated carbon prepared from the peel of Cucumis sativa fruit are presented in Table 1.The moisture content of the carbon was found to be $1.62 \%$ (Table 1 ). This would not influence the adsorptive power of activated carbon, It was then observed from the literature that if the moisture content of the adsorbent is more, it will dilute the action of activated carbon and it necessitates utilizing some extra load of carbon18. The decolorizing power was $47.0 \mathrm{mg} / \mathrm{g}$ which indicates that the carbon prepared by acid activation method has good adsorption capacity and it can be considered for adsorption of organic dyes.

\section{Effect of system $\mathrm{pH}$ on $\mathrm{CV}$ Uptake}

The $\mathrm{pH}$ of the system exerts profound influence on the adsorptive uptake of adsorbate molecule presumably due to its influence on the surface properties of the adsorbent and ionization/dissociation of the adsorbate molecule. Figure 1, shows the variations in the removal of dye from wastewater at various system $\mathrm{pH}$. From the figure, it is evident that the maximum removal of $(\mathrm{CV})$ color is observed at $\mathrm{pH} 7$. That may be attributed to the hydrophobic nature of the developed carbon which led to absorb hydrogen ions $(\mathrm{H}+)$ onto 
the surface of the carbon when immersed in water and make it positively charged. Low $\mathrm{pH}$ value (1.0 to 3.0) leads to an increase in $\mathrm{H}+$ ion concentration in the system and the surface of the activated carbon acquires positive charge by absorbing $\mathrm{H}+$ ions. On the other hand, increase of the $\mathrm{pH}$ value (7) led to increase of the number of negatively charged sites. As the $\mathrm{CRC}$ surface is negatively charged at high $\mathrm{pH}$, a significantly strong electrostatic attraction appears between the negatively charged carbon surface and cationic dye molecule leading to maximum adsorption of (CV) 19 from waste water. The lowest adsorption occurred at $\mathrm{pH}$ 2.0 and the greatest adsorption occurred at $\mathrm{pH} \sim 7.0$. Adsorbents surface would be positively charged up to $\mathrm{pH}<4$, and heterogeneous in the $\mathrm{pH}$ range $4-6$. Thereafter, it should be negatively charged. Moreover, the increasing in the adsorption of $(\mathrm{CV})$ with increasing of $\mathrm{pH}$ value is also due to the attraction between cationic dye and excess $\mathrm{OH}-$ ions in the solution.

Table 1. Characteristics of CCS.

\begin{tabular}{lc}
\hline Parameter & Value \\
\hline $\mathrm{pH}$ of $1 \%$ solution & 6.5 \\
Moisture content(\%) & 1.62 \\
Water soluble matter(\%) & 10.12 \\
Acid soluble matter(\%) & 8.07 \\
Decolorizing power $(\mathrm{mg} / \mathrm{g})$ & 47.0 \\
Conductivity & 0.92 \\
$\mathrm{pH}$ & 4.0 \\
\hline
\end{tabular}

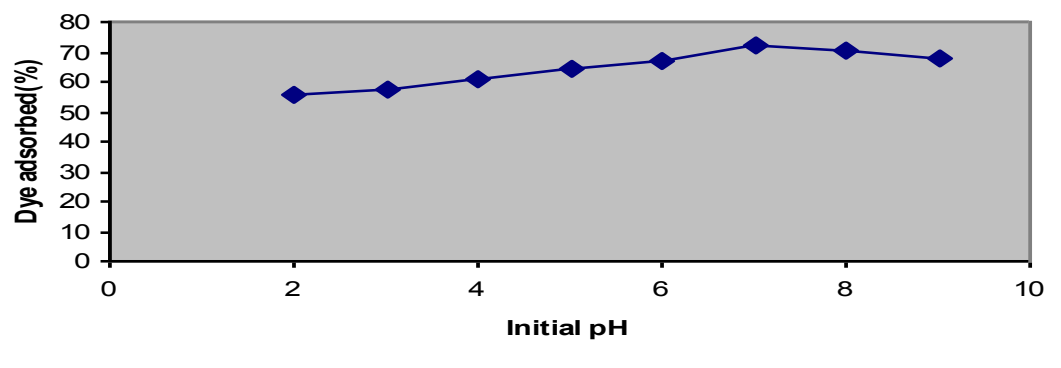

Figure 1. Effect of system $\mathrm{pH}$ on adsorption of CV $\left(100 \mathrm{mg} \mathrm{L}^{-1}\right)$ onto $\mathrm{CS}(0.2 \mathrm{~g} / 50 \mathrm{~mL})$ at room temperature $\left(27 \pm 2{ }^{\circ} \mathrm{C}\right)$, agitation speed $150 \mathrm{rpm}$ for the minimum contact time required to reach the equilibrium $(90 \mathrm{~min})$.

\section{Effect of adsorbent mass on CV adsorption}

The adsorption of $\mathrm{CV}$ on $\mathrm{CS}$ was studied by changing the quantity of adsorbent $(0.2,0.3$, $0.4,0.5$ and $0.6 \mathrm{~g} / 50 \mathrm{~mL})$ in the test solution while keeping the initial $(\mathrm{CV})$ concentration $100 \mathrm{mg} \mathrm{L}-1$ temperature $\left(27 \pm 2^{\circ} \mathrm{C}\right)$ and $\mathrm{pH} 7.0$ constant at contact times for $90 \mathrm{~min}$ Figure.2. The adsorption increased from $78.07 \%$ to $80.86 \%$, as the CCS dose increased from $0.2 \mathrm{~g}$ to $0.6 \mathrm{~g} / 50 \mathrm{~mL}$ at equilibrium time $90 \mathrm{~min}$. Maximum (CV) removal was achieved within 10-50 min after which $(\mathrm{CV})$ concentration in the reaction solution was almost constant. Increase in the adsorption with adsorbent dose can be attributed to increased (CV) surface area and availability of more adsorption sites, while the unit adsorbed of (CV) decreased with increase in CCS dose. 


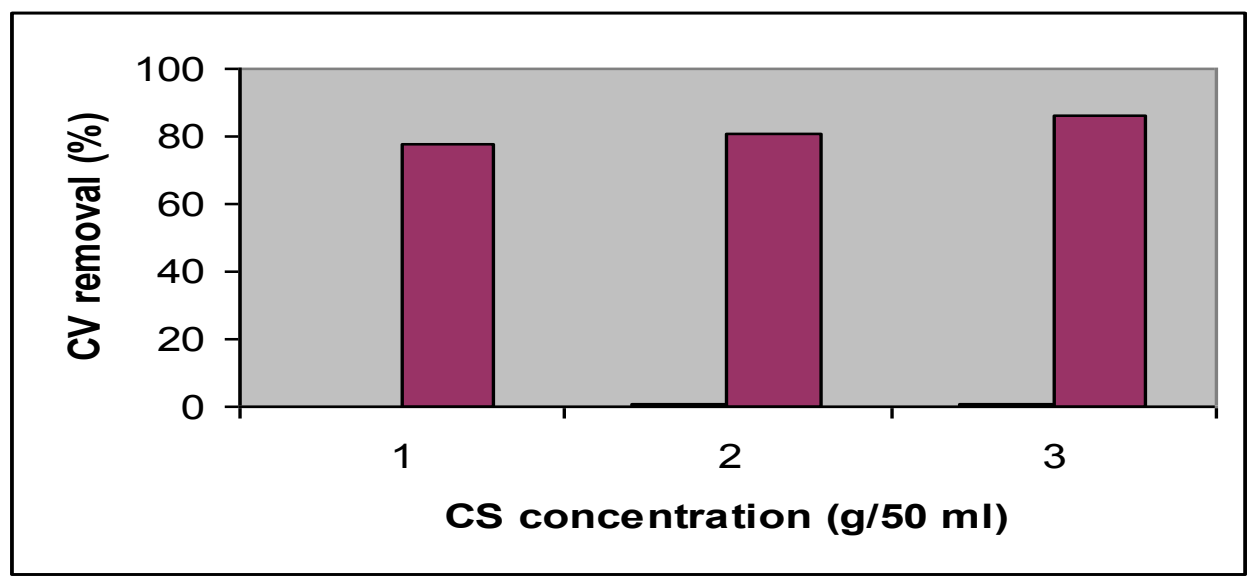

Figure 2. Effect of adsorbent concentration on $\mathrm{CV}$ removals $\left(C_{0}: 100 \mathrm{mg} \mathrm{L}^{-1}, \mathrm{pH} 7.0\right.$, agitation speed: $150 \mathrm{rpm}$, temperature: $27 \pm 2{ }^{\circ} \mathrm{C}$ ).

\section{Isotherm data analysis}

The relationship between the amount of a substance adsorbed at constant temperature and its concentration in the equilibrium solution is called the adsorption isotherm. The adsorption isotherm is important from both a theoretical and a practical point of view. In order to optimize the design of an adsorption system to remove the dye, it is important to establish the most appropriate correlations of the equilibrium data of each system. Equilibrium isotherm equations are used to describe the experimental adsorption data. The parameters obtained from the different models provide important information on the adsorption mechanisms and the surface properties and affinities of the adsorbent. The most widely accepted surface adsorption models for single-solute systems are the Langmuir and Freundlich models. The correlation with the amount of adsorption and the liquid-phase concentration was tested with the Langmuir, and Freundlich isotherm equations. Linear regression is frequently used to determine the best-fitting isotherm, and the applicability of isotherm equations is compared by judging the correlation coefficients.

\section{Langmuir isotherm}

The theoretical Langmuir isotherm 20 is valid for adsorption of a solute from a liquid solution as monolayer adsorption on a surface containing a finite number of identical sites. Langmuir isotherm model assumes uniform energies of adsorption onto the surface without transmigration of adsorbate in the plane of the surface 21 . Therefore, the Langmuir isotherm model was chosen for estimation of the maximum adsorption capacity corresponding to complete monolayer coverage on the adsorbent surface. The Langmuir non-linear equation is commonly expressed as followed:

$$
q_{\mathrm{e}}=\frac{Q_{\mathrm{m}} K_{\mathrm{a}} C_{\mathrm{e}}}{1+K_{\mathrm{a}} C_{\mathrm{e}}}
$$

In Eq. (2), $C_{e}$ and $q_{e}$ are as defined before in Eq.(1), Qm is a constant reflect a complete monolayer ( $\mathrm{mg} \mathrm{g}-1)$; $\mathrm{Ka}$ is adsorption equilibrium constant $(\mathrm{L} \mathrm{mg}-1)$ that is related to the apparent energy of sorption. The Langmuir isotherm Eq. (2) can be linearized into the following form 22,23 . 
Langmuir-1

$$
\frac{C_{\mathrm{c}}}{q_{\mathrm{e}}}=\frac{1}{K_{\mathrm{a}} Q_{\mathrm{m}}}+\frac{1}{Q_{\mathrm{m}}} \times C_{\mathrm{c}}
$$

A plot of $C_{e} / q_{e}$ versus Ce should indicate a straight line of slope 1/Qm and an intercept of 1/ (KaQm).

The results obtained from the Langmuir model for the removal of (CV) onto CCS are shown in Table 2. The correlation coefficients reported in Table 2 showed strong positive evidence on the adsorption of (CV) onto CCS follows the Langmuir isotherm. The applicability of the linear form of Langmuir model to CCS was proved by the high correlation coefficients $\mathrm{R} 2>0.998$. This suggests that the Langmuir isotherm provides a good model of the sorption system. The maximum monolayer capacity Qm obtained from the Langmuir is

$34.24 \mathrm{mg} \mathrm{g}-1$.

Table 2. Comparison of the coefficients isotherm parameters for CV adsorption onto CS.

\begin{tabular}{ll}
\hline Isotherm model & Cucumis sativa activated carbon concentrations $(\mathrm{g} / 50 \mathrm{~mL})$ \\
& 0.2 \\
\hline Langmuir & \\
$Q_{\mathrm{m}}\left(\mathrm{mg} \mathrm{g}^{-1}\right)$ & 34.24 \\
$K_{\mathrm{a}}\left(\mathrm{L} \mathrm{mg}^{-1}\right)$ & 0.066 \\
$R^{2}$ & 0.9979 \\
\hline Freundlich & \\
$1 / n$ & 0.3775 \\
$K_{\mathrm{F}}\left(\mathrm{mg} \mathrm{g}^{-1}\right)$ & 5.851 \\
$R^{2}$ & 0.9854 \\
\hline
\end{tabular}

The Freundlich isotherm

The Freundlich isotherm model 24 is the earliest known equation describing the adsorption process. It is an empirical equation can be used for non-ideal sorption that involves heterogeneous adsorption. The Freundlich isotherm can be derived assuming a logarithmic decrease in the enthalpy of adsorption with the increase in the fraction of occupied sites and is commonly given by the following non-linear equation:

$$
q_{\mathrm{e}}=K_{\mathrm{F}} C_{\mathrm{e}}^{1 / n}
$$

where KF is a constant for the system, related to the bonding energy. KF can be defined as the adsorption or distribution coefficient and represents the quantity of dye adsorbed onto adsorbent for unit equilibrium concentration. $1 / \mathrm{n}$ is indicating the adsorption intensity of dye onto the adsorbent or surface heterogeneity, becoming more heterogeneous as its value gets closer to zero. A value for $1 / \mathrm{n}$ below 1 indicates a normal Langmuir isotherm while $1 / \mathrm{n}$ above 1 is indicative of cooperative adsorption. Eq. (4) can be linearized in the logarithmic form (Eq.(5)) and the Freundlich constants can be determined:

$$
\log q_{\mathrm{e}}=\log K_{\mathrm{F}}+\frac{1}{n} \log C_{\mathrm{e}}
$$


The applicability of the Freundlich adsorption isotherm was also analyzed, using the same set of experimental data, by plotting $\log (\mathrm{qe})$ versus $\log (\mathrm{Ce})$. The data obtained from linear Freundlich isotherm plot for the adsorption of the (CV) onto CCS is presented in Table 2. The correlation coefficients $(>0.985)$ showed that the Freundlich model is comparable to the Langmuir model. The $1 / \mathrm{n}$ is lower than 1.0 , indicating that $(\mathrm{CV})$ is favorably adsorbed by CCS.

\section{Kinetic models applied to the adsorption of (CV) onto CCS}

Several steps can be used to examine the controlling mechanism of adsorption process such as chemical reaction, diffusion control and mass transfer; kinetic models are used to test experimental data from the adsorption of (CV) onto CCS. The kinetics of (CV) adsorption onto CCS is required for selecting optimum operating conditions for the full-scale batch process. The kinetic parameters, which are helpful for the prediction of adsorption rate, give important information for designing and modeling the adsorption processes. Thus, the kinetics of $(\mathrm{CV})$ adsorption onto CCS were analyzed using pseudo-first-order24, pseudosecond-order 25 kinetic models. The conformity between experimental data and the modelpredicted values was expressed by the correlation coefficients (R2, values close or equal to 1). The relatively higher value is the more applicable model to the kinetics of (CV) adsorption onto CCS.

\section{Pseudo-first-order equation}

The adsorption kinetic data were described by the Lagergren pseudo-first-order model25, which is the earliest known equation describing the adsorption rate based on the adsorption capacity. The differential equation is generally expresses a follows:

$$
\frac{\mathrm{d} q_{t}}{\mathrm{~d} t}=k_{1}\left(q_{\mathrm{e}}-q_{t}\right)
$$

where qe and qt are the adsorption capacity at equilibrium and at time $t$, respectively (mg g-1), $\mathrm{k} 1$ is the rate constant of pseudo-first-order adsorption ( $\mathrm{L} \mathrm{min}-1)$. Integrating Eq. (12) for the boundary conditions $t=0-t$ and $q t=0-q t$ gives

$$
\log \left(\frac{q_{\mathrm{e}}}{q_{\mathrm{e}}-q_{i}}\right)=\frac{k_{1}}{2.303} t
$$

Eq. (13) can be rearranged to obtain the following linear form:

$$
\log \left(q_{\mathrm{c}}-q_{i}\right)=\log \left(q_{\mathrm{e}}\right)-\frac{k_{1}}{2.303} t
$$

In order to obtain the rate constants, the values of $\log (q \mathrm{e}-\mathrm{qt})$ were linearly correlated with $\mathrm{t}$ by plot of $\log (\mathrm{qe}-\mathrm{qt})$ versus $\mathrm{t}$ to give a linear relationship from which $\mathrm{k} 1$ and predicted qe can be determined from the slope and intercept of the plot, respectively Figure 3 . The variation in rate should be proportional to the first power of concentration for strict surface adsorption. However, the relationship between initial solute concentration and rate of adsorption will not be linear when pore diffusion limits the adsorption process. Figure4 
shows that the pseudo-first-order equation fits well for the first $50 \mathrm{~min}$ and thereafter the data deviate from theory. Thus, the model represents the initial stages where rapid adsorption occurs well but cannot be applied for the entire adsorption process. Furthermore, the correlation coefficient R2 are relatively low for most adsorption data Table 3 . This shows that the adsorption of (CV) onto CCS cannot be applied and the reaction mechanism is not a first-order reaction.

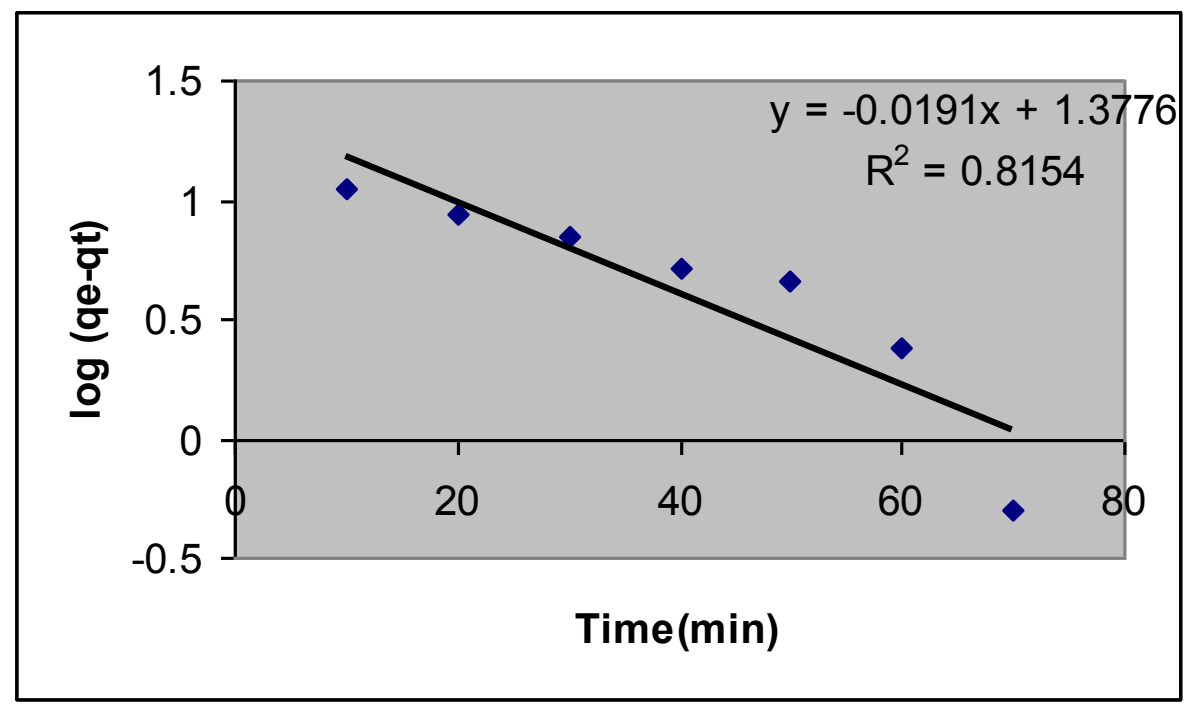

Figure 3. Pseudo-first-order kinetics for $\mathrm{CV}$ adsorption onto CS. Conditions: adsorbent dosage $0.2 \mathrm{~g} / 50 \mathrm{~mL}, \mathrm{pH} 7.0$, temperature $27 \pm 2{ }^{\circ} \mathrm{C}$.

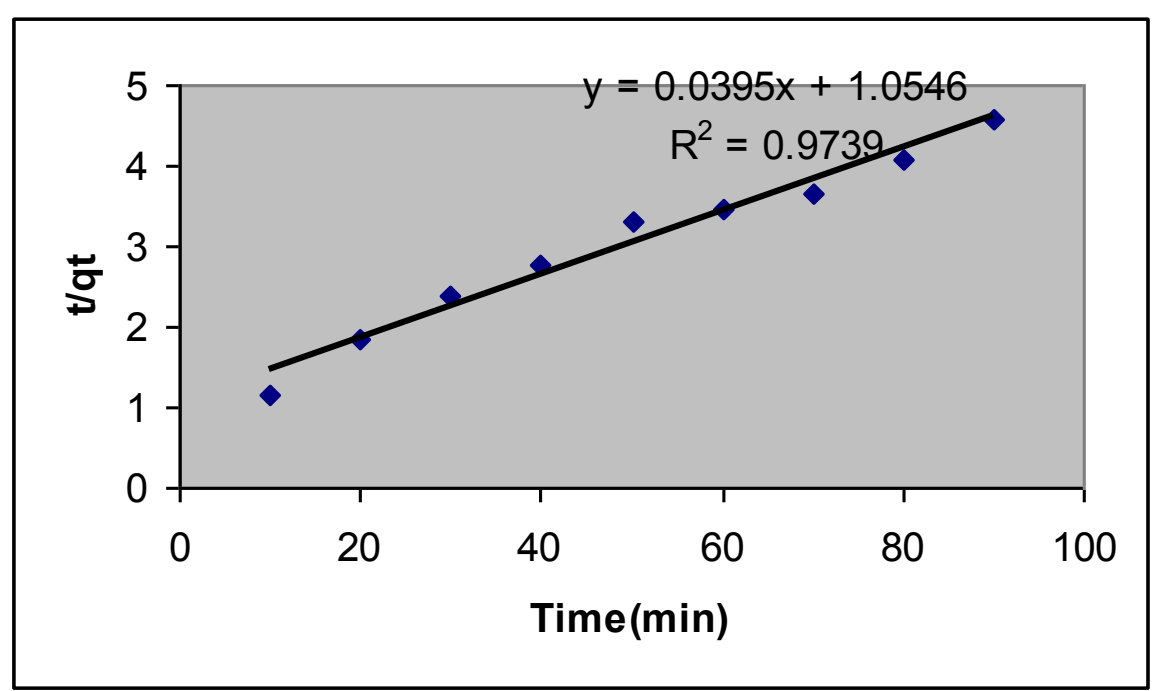

Figure 4. Plot of the pseudo-second-order model at different initial CVconcentrations, CS $0.2 \mathrm{~g} / \mathrm{mL}, \mathrm{pH} 7.0$, temperature $27 \pm 2{ }^{\circ} \mathrm{C}$. 
Table 3. Comparison of the first- and second-order adsorption rate constants and calculated and experimental $q_{\mathrm{e}}$ values for $100 \mathrm{mg} / \mathrm{L}$ initial CV and CS $(0.2 \mathrm{~g} / 50 \mathrm{~mL})$.

\begin{tabular}{|c|c|c|c|c|c|c|c|c|}
\hline \multicolumn{3}{|c|}{ Parameter } & \multicolumn{3}{|c|}{ First-order kinetic model } & \multicolumn{3}{|c|}{ Second-order kinetic model } \\
\hline $\begin{array}{c}\mathrm{CS} \\
\text { concentration } \\
(\mathrm{g} / 50 \mathrm{~mL})\end{array}$ & $\begin{array}{c}\mathrm{Cv} \\
\left(\mathrm{mg} \mathrm{L}^{-1}\right)\end{array}$ & $\begin{array}{c}q_{\mathrm{e}} \\
\text { (experimental) }\end{array}$ & $\overline{k_{1}}$ & $\begin{array}{c}q_{\mathrm{e}} \\
\text { (calculated } \\
\text { ) }\end{array}$ & $R^{2}$ & $k_{2}$ & $\begin{array}{c}q_{\mathrm{e}} \\
\text { (calculated) }\end{array}$ & $R^{2}$ \\
\hline 0.2 & 100 & 15.25 & $\begin{array}{c}0.0 \\
4\end{array}$ & 23.85 & $\begin{array}{c}0.815 \\
4\end{array}$ & $\begin{array}{c}0.00 \\
1\end{array}$ & 25.31 & $\begin{array}{c}0.97 \\
39\end{array}$ \\
\hline
\end{tabular}

$\mathrm{k}_{1}\left(\min ^{-1}\right), \mathrm{k}_{2}\left(g(m g \min )^{-1}\right), \mathrm{q}_{e}\left(m g g^{-1}\right)$.

\section{Pseudo-second-order equation}

The adsorption kinetic may be described by the pseudo-second-order model 25 . The differential equation is generally given as follows:

$$
\frac{\mathrm{d} q_{t}}{\mathrm{~d} t}=k_{2}\left(q_{\mathrm{e}}-q_{t}\right)^{2}
$$

where $\mathrm{k} 2(\mathrm{~g}(\mathrm{mg} \mathrm{min})-1)$ is the second-order rate constant of adsorption. Integrating Eq. (15) for the boundary conditions $\mathrm{qt}=0-\mathrm{qt}$ at $\mathrm{t}=0-\mathrm{t}$ is simplified as can be rearranged and linearized to obtain:

$$
\left(\frac{t}{q_{t}}\right)=\frac{1}{k_{2} q_{\mathrm{e}}^{2}}+\frac{1}{q_{\mathrm{e}}}(t)
$$

If the second-order kinetics is applicable, then the plot of $\mathrm{t} / \mathrm{qt}$ versus $\mathrm{t}$ should show a linear relationship. Values of $\mathrm{k} 2$ and equilibrium adsorption capacity qe were calculated from the intercept and slope of the plots of $t / q t$ versus $t$ Figure 4. The linear plots of $t / q t$ versus $t$ show good agreement between experimental and calculated qe values at different initial (CV) and adsorbent concentrations Table 3 . The correlation coefficients for the second-order kinetic model are greater than 0.974 , which led to believe that the pseudo-second-order kinetic model provided good correlation for the bioadsorption of different initial of (CV) onto CCS.

\section{Conclusion}

The results of this investigation show that the Cucumis sativa has a suitable adsorption capacity for the removal of $(\mathrm{CV})$ from aqueous solutions. The equilibrium adsorption is practically achieved in $90 \mathrm{~min}$. The experimental results were analyzed by using Langmuir and Freundlich isotherm models and the correlation coefficients for Langmuir and Freundlich equations are well fitted. Adsorption behavior is described by a monolayer Langmuir-type isotherm. The kinetic study of (CV) onCCS was performed based on pseudofirst-order and pseudo-second-order equations. The data indicate that the adsorption kinetics follow the pseudo-second-order rate. The present study concludes that the CCS could be employed as low-cost adsorbents as alternatives to commercial activated carbon for the removal of color and dyes from water and wastewater. 


\section{References}

1. Crini G., Non-conventional low-cost adsorbents for dye removal: a review, Bioresour. Technol. 2006, 97, 1061-1085.

2. Robinson T., McMullan G., Marchant R. and Nigam P., Remediation of dyes in textile effluent: a critical review on current treatment technologies with a proposed alternative, Bioresour. Technol 2001, 77, 247-255.

3. Aksu Z., Application of biosorption for the removal of organic pollutants: a review, Process Biochem(2005), 40 , 997-1026.

4. Han R.P., Zhang J.H., Zou W.H., Shi J and Liu H.M., Equilibrium biosorption isotherm for lead ion on chaff, J. Hazard. Mater. 2005, $125,266-271$.

5. Gupta V.K., Ali I., Suhas D. and Mohan, Equilibrium uptake and sorption dynamics for the removal f a basic dye (basic red) using low cost adsorbents, J. Colloid Interface Sci 2003, $265,257-264$.

6. Ho Y.S., Chiu W.T. and Wang C.C., Regression analysis for the sorption isotherms of basic dyes on sugarcane dust, Bioresour. Technol 2005, 96, 1285-1291.

7. Kumar K.V., Comparative analysis of linear and non-linear method of estimating the sorption isotherm parameters for malachite green onto activated carbon, J. Hazard. Mater.2006, 136 , 197-202.

8. Ho Y.S. Second-order kinetic model for the sorption of cadmium onto tree fern: a comparison of linear and non-linear methods, Water Res. 2006, 40, 119-125.

9. Han R.P., Wan Y., Zou W.H., Wang Y.F. and Shi J., Comparison of linear and nonlinear analysis in estimating the Thomas model parameters for methylene blue adsorption onto natural zeolite in fixed-bed column, J. Hazard. Mater.2007, 145, 331335.

10. Goel J., Kadirvelu K., Rajagopal C. and Garg V.K., Removal of lead(II) by adsorption using treated granular activated carbon: batch and column studies, J. Hazard. Mater. 2005,125, 211-220.

11. Gupta V.K., Jai R. and Varshney S., Removal of reactofix golden yellow 3 RFN from aqueous solution using wheat husk - an agricultural waste, J. Hazard. Mater. 2007, 142, 443-448.

12. Han R.P., Zou W.H., Li H.K, Li Y.H. and Shi J., Copper(II) and lead(II) removal from aqueous solution in fixed-bed columns by manganese oxide coated zeolite, J. Hazard. Mate .2006, 137 1569-1576.

13. Özer A., Akkaya G. and Turabik M., The biosorption of Acid Red 337 and Acid Blue 324 on Enteromorpha prolifera: the application of nonlinear regression analysis to dye biosorption, Chem. Eng. J 2005, 112, 181-190.

14. Yan G.Y. and Viraraghavan T., Heavy metal removal in a biosorption column by immobilized M. rouxii biomass, Bioresour. Technol.2001, 78 243-249.

15. Han R.P., Zou W.H., Yu W.H., Cheng S.J., Wang Y.F. and Shi J., Biosorption of methylene blue from aqueous solution by fallen phoenix tree's leaves, J. Hazard. Mater. 2007, 141 156-162.

16. Han R.P., Wang Y.F., Han P., Shi, J. Yang and Lu Y.S., Removal of methylene blue from aqueous solution by chaff in batch mode, J. Hazard. Mater. 2006, 137, 550-557.

17. Santhi T., Manonmani S., Smith T., Sugirtha D. and Mahalakshmi K., Uptake of cationic dyes from aqueous solution by bioadsorption onto granular cucumis sativa, $J$. Applied.Sci.in Environ. Sanit. 2009, 4, 29-35.

18. sugunadevi SR, Sathis kumar M, Shanthi K, Kadirvelu K and Pattabhi S, Indian J Environ Protection, 2002, 22, 500- 505. 
19. Tabrez A. K., Imran A., Ved V.S. and Sangeeta S., Utilization of fly ash as low-cost adsorbent for the removal of methylene blue, malachite green and rhodamine B dyes from textile wastwater, J. Envirn. Production Science. 2009, 3, 11-22.

20. Ahmed EI Nem, Ola Abdelwahab, Amany EI-Sikaily and Azza Khaled, Removal of direct blue- 86 from from aqueous solution by new activated carbon developed from orange peel, J. Hazard. Mater. 2009,161(1), 102-110.

21. I. Langmuir I., The constitution and fundamental properties of solids and liquids, J. Am. Chem. Soc. 1916, 38, 2221-2295.

22. Doğan M., Alkan M. and Onganer Y., Adsorption of methylene blue from aqueous solution onto perlite, Water Air Soil Pollut. (2000),120 , 229-249.

23. Kinniburgh D.G., General purpose adsorption isotherms, Environ. Sci. Technol. (1986),20 , 895-904.

24. Lagergren S., Zur theorie dersogenannten adsorption geloster stoffe kungliga svenska vetenskapsakademiens, Handlingar. (1898), 24, 1-39.

25. Ho Y.S., McKay G., Was D.A.J and Foster C.F., Study of the sorption of divalent metal ions on to peat, Adsorp. Sci. Technol. 2000, 18, 639-650.

26. 26.Chien S.H. and Clayton W.R., Application of Elovich equation to the kinetics of phosphate release d sorption on soils, Soil Sci. Soc. Am. J. 1980, 44, 265-268.

27. Sparks D.L., Kinetics of Reaction in Pure and Mixed Systems, in Soil Physical Chemistry, CRC Press, Boca Raton 1986. 


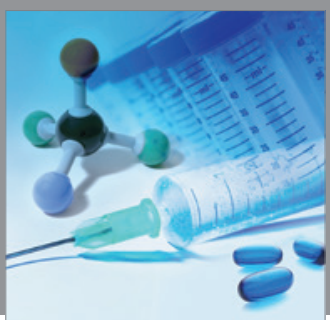

International Journal of

Medicinal Chemistry

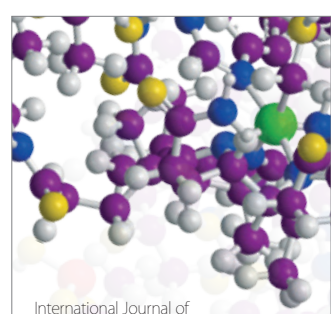

Carbohydrate Chemistry

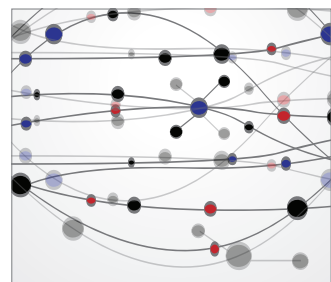

The Scientific World Journal
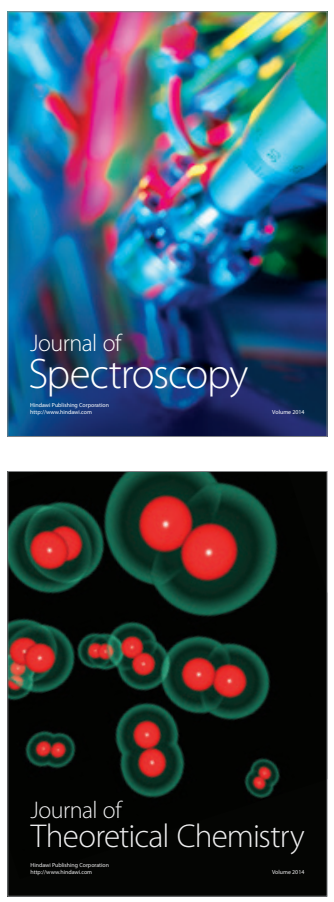
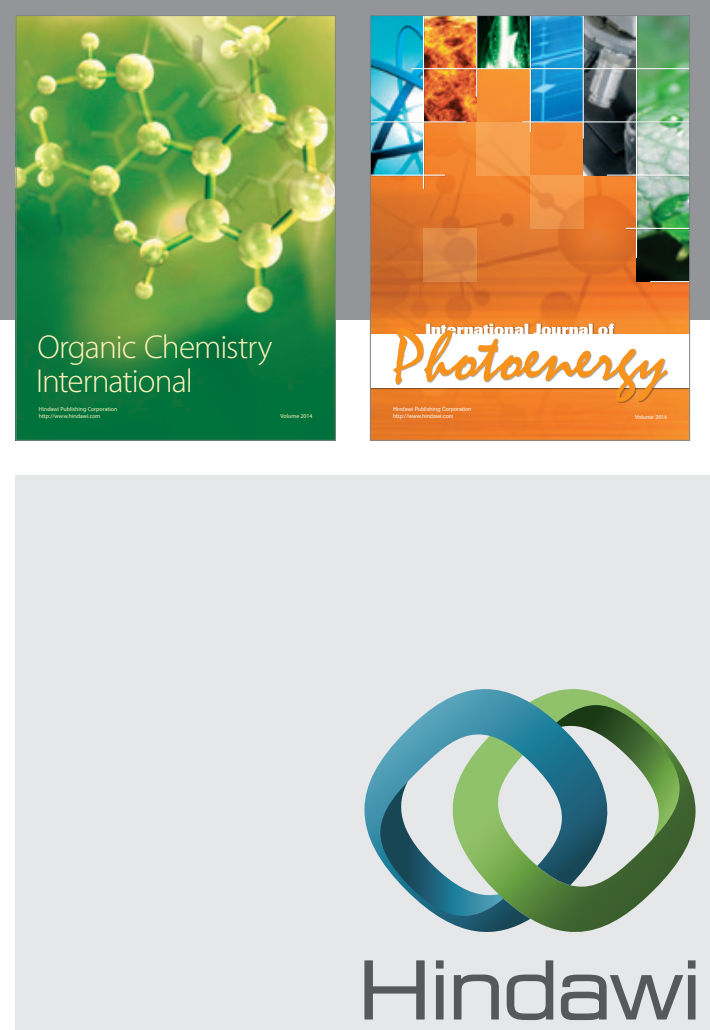

Submit your manuscripts at

http://www.hindawi.com
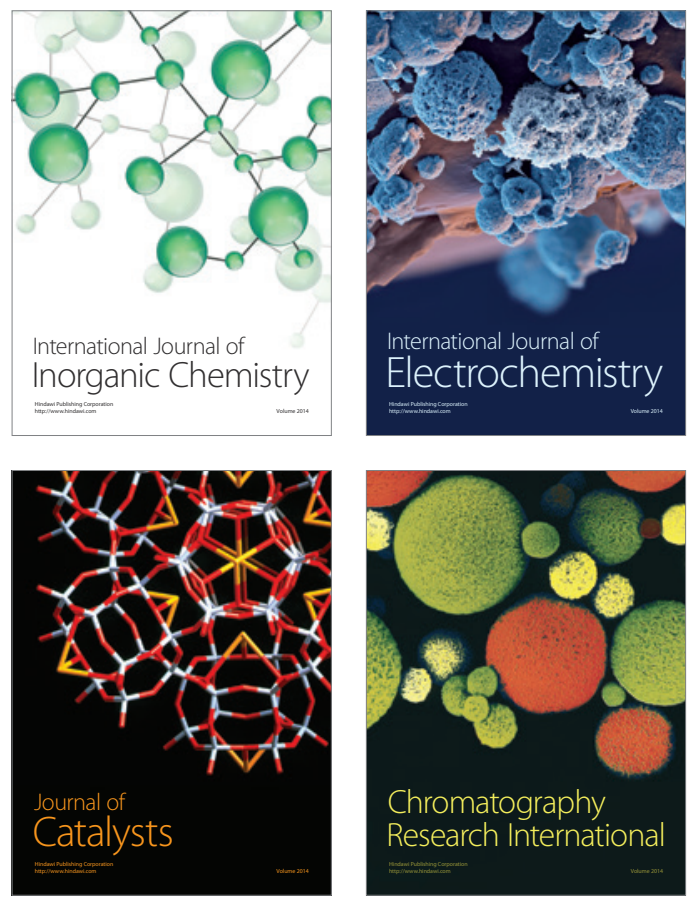
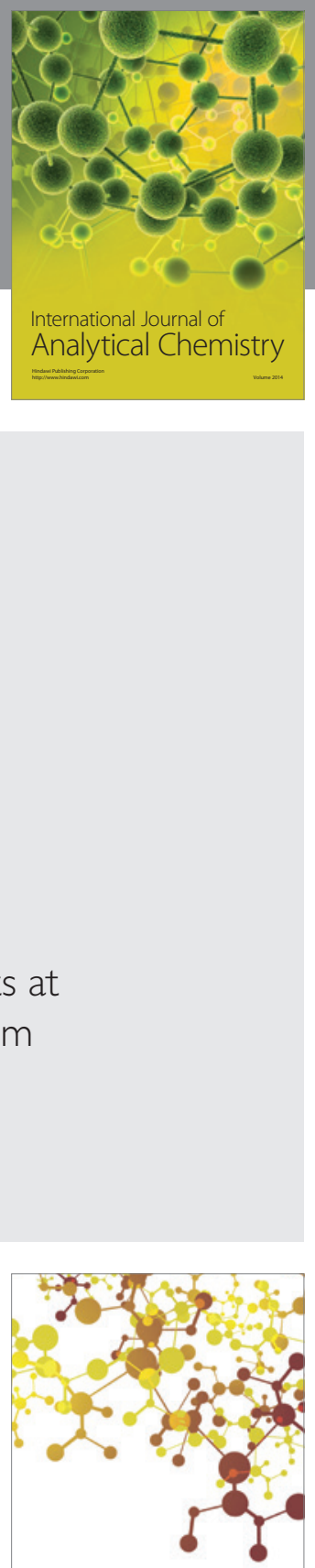

Journal of

Applied Chemistry
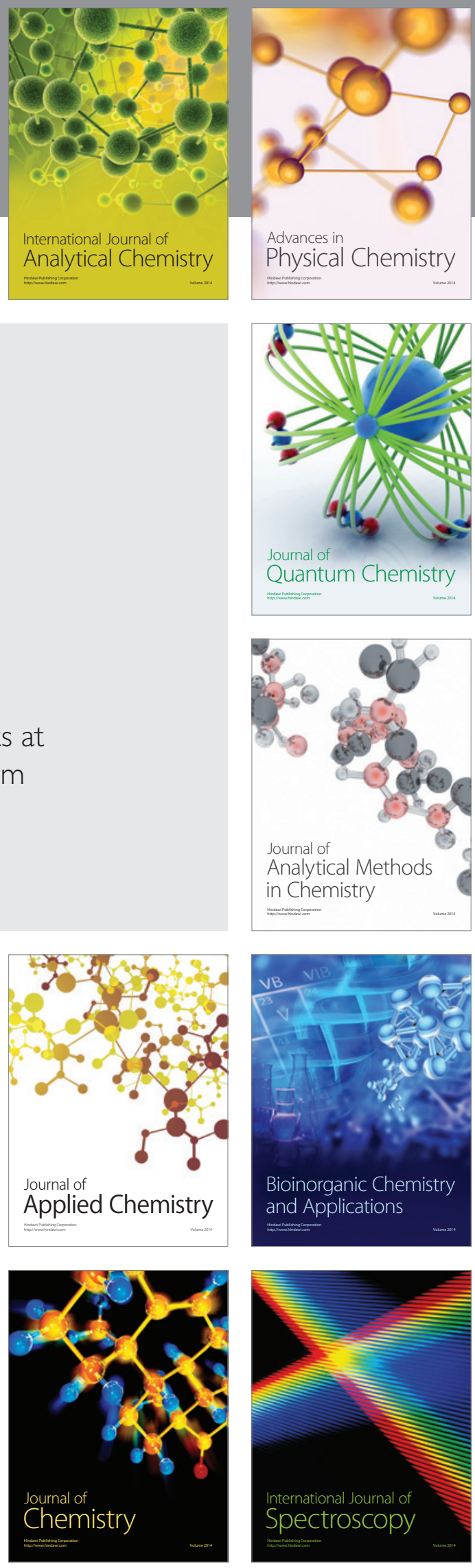